\title{
WP 2002-38
}

October 2002

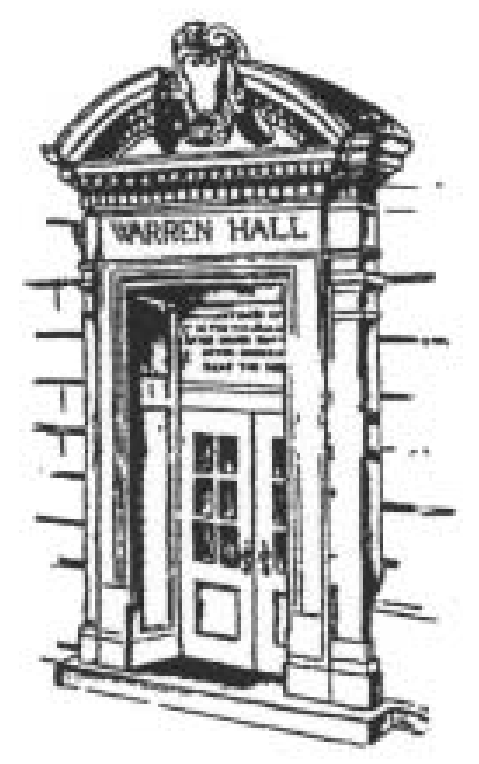

\section{Working Paper}

Department of Applied Economics and Management

Cornell University, Ithaca, New York 14853-7801 USA

\section{Social Identity and Manipulative Interhousehold Transfers Among East African Pastoralists}

Marieke Huysentruyt

London School of Economics

Christopher B. Barrett

Cornell University

John G. McPeak

Cornell University and Syracuse University 
It is the Policy of Cornell University actively to support equality of educational and employment opportunity. No person shall be denied admission to any educational program or activity or be denied employment on the basis of any legally prohibited discrimination involving, but not limited to, such factors as race, color, creed, religion, national or ethnic origin, sex, age or handicap. The University is committed to the maintenance of affirmative action programs which will assure the continuation of such equality of opportunity. 


\title{
Social Identity and Manipulative Interhousehold Transfers Among East African Pastoralists
}

\author{
Marieke Huysentruyt \\ London School of Economics \\ Christopher B. Barrett* \\ Cornell University \\ John G. McPeak \\ Cornell University and Syracuse University
}

October 2002 Revised Draft
* Corresponding author at 315 Warren Hall, Ithaca, NY 14853-7801 USA, email: cbb2@cornell.edu, telephone: 607-255-4489, fax: 607-255-9984

We thank Paul Cichello, Marlene Decker and members of the Pew Economics team for comments on an earlier draft, Arthur Brooks and Peter Little for helpful discussions, and The Pew Charitable Trusts, and the US Agency for International Development's (USAID) BASIS Collaborative Research Support Program (CRSP) and Global Livestock CRSP, each through the Office of Agriculture and Food Security, Global Bureau, USAID, and the Strategies and Analyses for Growth and Access (SAGA) cooperative agreement through Africa Bureau, USAID, for generous financial support. The views expressed here are those of the authors and do not represent any official agency.

(c) Copyright 2002 by Marieke Huysentruyt, Christopher B. Barrett and John G. McPeak. All rights reserved. Readers may make verbatim copies of this document for non-commercial purposes by any means, provided that this copyright notice appears on all such copies. 


\section{Social Identity and Manipulative Interhousehold Transfers Among East African Pastoralists}

Abstract: We model interhousehold transfers between nomadic livestock herders as the statedependent consequence of individuals' strategic interdependence resulting from the existence of multiple, opposing externalities. A public good security externality among individuals sharing a social (e.g., ethnic) identity in a potentially hostile environment creates incentives to band together. Self-interested interhousehold wealth transfers from wealthier herders to poorer ones may emerge endogenously within a limited wealth space as a means to motivate accompanying migration by the recipient. The distributional reach and size of the transfer are limited, however, by a resource appropriation externality related to the use of common property grazing lands. When this effect dominates, it can induce distributionally regressive transfers from ex ante poor households who want to relieve grazing pressures caused by larger herds. As compared to the extant literature on transfers, our model appears more consistent with the limited available empirical evidence on heterogeneous and changing transfers patterns among east African pastoralists. 


\section{Introduction}

Scholars' explanations of interhousehold transfers serve as allegories for our understanding of human nature and the social environment that conditions human behavior. This topic has consequently been a source of dispute within most disciplines in the humanities and the social sciences. Since at least the $17^{\text {th }}$ century, philosophers have disagreed as to whether altruism is merely apparent, meaning that even states of mind that are directed towards the welfare of others ultimately aim at advancing one's own pleasure (Hobbes 1650, Hobbes 1651, Butler 1726). Within anthropology, substantivists such as Scott (1976) have long argued that transfers arise from a "moral economy" in which prevailing ethical values such as the virtue of generosity and individuals' primordial right to subsistence assure support for the poor, while rationalists such as Popkin (1979) have countered that what appears to be a moral economy can be wholly explained by self-interested, opportunistic individual behavior. A fierce debate likewise rages within contemporary theology on these questions, drawing on Mauss' classic The Gift (1966) to argue whether humans ever undertake non-self-interested, non-manipulative giving (Milbank 1997, Caputo and Scanlon 1999). Examples from other disciplines are not difficult to find.

Economists have engaged this debate as well. Some explain interhousehold transfers as the result of altruistic preferences or some sort of moral code that constrains individual choice out of a sense of fairness or noblesse oblige, perhaps complemented by the "warm glow" effects the giver enjoys from impure giving (Phelps 1975, Andreoni 1989, Samuelson 1993, Coate 1995, Smith et al. 1995, Kirchler et al. 1996, Barrett 1999). Others explain transfers as an endogenously supportable insurance mechanism adopted by purely self-interested individuals to cope with an environment of imperfect information and missing financial markets in which individuals interact repeatedly (Kimball 1988, Fafchamps 1992, Platteau 1992, Coate and Ravallion 1993, Townsend 
1994). ${ }^{1}$ We accept the veracity of these two canonical models in explaining some interhousehold transfers. Surely some people provide insurance for one another and some can at least occasionally be gracious toward those who suffer in their midst. However, the limited empirical evidence among the East African pastoralists we have been studying intensely for the past several years casts doubt on the completeness and perhaps even the relative importance of these two explanations of transfers, as we discuss in the next section.

This paper therefore develops an alternative model in which transfers are a manipulative gesture motivated by the strategic interdependence of individuals sharing both access to a productive resource and a common social identity in a potentially hostile environment. This is explicitly not pure altruism, because individuals value only their own welfare. Nor is it impure altruism due to "warm glow effects" (Andreoni 1989), wherein giving is intrinsically selfinterested. In our model, giving is intrinsically costly but can nonetheless be instrumentally valuable to the giver if it motivates the recipient to undertake a self-interested action that has a positive spillover benefit for the donor. Put differently, transfers can serve as costly but desirable coordinating mechanisms among interdependent actors.

Nor is this a patron-client relationship, in which marked inequalities in wealth, status or power give rise to vertical insurance systems or exchange of nontraded services (e.g., protection) for tradable goods and services such as material tribute or labor (Scott 1972, Fafchamps 1992, Carter 1997, Platteau 1995, Ray 1998). In our model, no exchange of services occurs, redistribution occurs only with limited inequality in wealth and can be either distributionally progressive or regressive. Transfers occur within a limited wealth space purely due to the material self-interest of both the donor and the recipient. Finally, this is neither insurance nor investment in social capital, because ours is a static model in which transfers do not occur in

\footnotetext{
${ }^{1}$ A variation on this theme would be that transfers represent current investment in social capital that is expected to pay future dividends, albeit likely in a form other than that of the original transfer. This is akin to models of political campaign contributions, wherein donors make financial gifts today with the expectation of preferential treatment on policy decisions at some future date.
} 
response to idiosyncratic shocks to agents' wealth or income and there is no opportunity for reciprocal behavior.

In our model, a voluntary, self-interested wealth transfer is essentially a side payment for a migration decision the recipient only prefers ex post, that is after having received the 'gift'. While the transfer may well strengthen the recipient's inclination towards 'cooperative' behavior (Fehr et al. 1997, Akerlof 1982) or elicit his penchant for reciprocity (Bowles et al. 1997), the 'service' the recipient offers - through the migration choice he makes - is unambiguously in his own interest. Like in the Bernheim et al.(1985) model of strategic bequests, the wealth transfer is strategic in that it influences the recipient's choice of actions. Transfers are consequently manipulative in nature. But unlike the individually costly services - such as care, visits, attention (Cox 1987, Bernheim et al. 1985), sense of worth and status (Offer 1997) - considered in most investigations of exchange-based motives for private transfers, in our model, the service returned by the recipient to the giver is not costly at all, as it merely originates in the externality effects generated by the recipient's self-interested, post-transfer choice. ${ }^{2}$ This notion of manipulative gifts seems fitting with a variety of exchanges, such as foreign aid and international support (Lundborg 1998).

We motivate and situate our model in the context of east African pastoralists whose livelihoods depend on the extensive grazing of livestock. One novelty of the current study is that we identify how transfers can be risk reducing and/or productivity enhancing for the donor household. As noted by Goodhue and McCarthy (1999), the borders of common property areas are not always clearly defined. We argue that the flexible and contested nature of these boundaries creates an incentive for donor households to support recipient households. Donor households have an interest in ensuring that "our group" remains big enough to maintain access

\footnotetext{
${ }^{2}$ Our 'service' does share with previous models the important feature of having no close market substitutes. In our context, security is not a 'commodity' on sale. Hiring armed mercenaries is simply not a wise option in light of the commercialization of cattle rustling and the evidence that cattle rustlers often exploit inside information (Fleisher 2000).
} 
to contested production areas and to repel attacks by "other groups". Insufficient livestock not only threatens a household with a food security crisis, it also threatens neighboring households with the potential loss of an ally in a hostile environment. As a result, progressive transfers may occur from richer to poorer households. The production externality commonly assumed to exist in common property models is consequently not the full story of strategic interdependence in certain settings. This production externality must be balanced against the possibility that there is "safety in numbers". As many common property resource areas are vast and only loosely controlled by a state exercising police authority, concerns about security in such areas may be important.

Yet common property resource externalities plainly matter. Indeed, we show that as long as some basic level of public goods are provided in particular locations, such appropriation externalities may give rise to distributionally regressive transfers from poorer to wealthier households. We further argue that observed declines in mobility and transfers in pastoral areas of east Africa can be explained as the result of the exogenous, but local, provision of public goods. As the state expands its reach into pastoral areas, it brings both security in the form of police forces and some low-level safety net in the form of food aid. These services are often confined to areas around towns. This leads certain subpopulations to become more reliant on exogenously supplied public goods, while others remain more reliant on the endogenous private provision of public goods. The gradual reduction of the volume of transfers and mobility in pastoral societies is then at least partially due to limited, localized provision of public goods. Finally, our model offers insights into how the incomplete provision of public services can lead to non-convex production functions commonly associated with poverty traps.

The remainder of the paper is structured as follows. Section 2 provides some background on pastoralism in the east African ASAL as a means to motivate both the search for an alternative economic explanation of interhousehold transfers and the assumptions that underpin our model. 
Section 3 then develops a simple model of myopic migration choice from those stylized facts and emerges with several important propositions. Section 4 then relaxes the previous section's exogeneity assumption with respect to others' behavior, drawing out the implications for interrelated migration and transfer choices in a noncooperative, three-agent game. Section 5 concludes by reflecting on the policy implications of this alternative explanation for manipulative interhousehold transfers.

\section{Background on East African Pastoralists}

We develop our model around the example of livestock transfers between nomadic pastoralists in the arid and semi-arid lands (ASAL) of east Africa. These pastoralists' livelihoods depend almost entirely on extensive livestock production in regions subject to frequent drought, violent intergroup conflict, and famine. A household's livestock herd therefore represents virtually all of its non-labor wealth. Traditionally, ASAL herders migrated with their herds in search of pasture and water for their animals. Herders survived mainly by consuming the milk, meat, and blood of their herds. Few permanent settlements existed in pastoral areas in the pre-colonial and colonial eras. The few settlements that existed were almost exclusively occupied by traders. Pastoral households would temporarily occupy areas near these trading points when conditions were favorable and move on as other areas become more favorable.

The boundaries within which households moved were flexible and contested. The process of groups pushing into new areas or being pushed out of old areas was a constant fact of life (Sobania 1978, Robinson 1984, Tablino 1999). Areas that were accessible to members of a group at one point were not guaranteed to be accessible in the future. Defense of a given area and of a group's herds was the responsibility of group members, as was the potential conquest of neighboring areas. Membership in a social group was thus critical for ensuring access to grazing lands and security of one's wealth. 
Group membership also involved access to a set of livestock transfer arrangements. East African pastoral societies are rich in the variety of social mechanisms that exist to allow transfer of animals from one herder to another (Torry 1973, Schneider 1979, Sperling, McCabe, Little 1992, Ensminger 1994). One objective of these transfers was to allow households who had suffered unexpected herd losses to reestablish a herd, thus helping them meet their consumption needs over time. These transfers also served to keep people who had lost their animals as mobile members of the group able to help provide for the common defense of herds and grazing areas. ${ }^{3}$

Nonetheless, transfers are not always large and they typically do not go to the very poor. Desta's (1999) data show that among Borana pastoralists in southern Ethiopia, the poorest and richest quartiles of herders were only one-sixth and one-fourth as likely, respectively, to receive livestock gifts or loans as the central half of the wealth distribution. McPeak (2001a) finds that richer herders are considerably more likely to receive transfers their poorer neighbors. Moreover, transfers often flow from the poor to relatively better off (albeit still poor) households (Lybbert et al. 2001). For example, among Gabra pastoralists in northern Kenya, our data show that 34 percent of livestock transfers were given by households possessing a smaller herd than the recipient household.

It is difficult to reconcile the extant economic literature on altruistic transfers with these facts about contemporary east African pastoralists. For example, the core prediction of a model of selfless giving - especially if (potentially impure) altruism is a normal good - would be that giving increases with wealth and its corollary, that transfers flow disproportionately to the poorest agents within the system. This contrasts with contemporary empirical evidence that at least

\footnotetext{
${ }^{3}$ As noted by historical studies, during periods of severe covariate shock such as the crisis of the late 1800 's, endogenous restocking was impossible (Waller, Robinson). Households who lost their herds often also lost their status as a member of the pastoral group. For example, Samburu nomads who lost their animals became Dorobo hunter and gatherers. The Wata hunter and gatherers absorbed former Gabra herders. Former Maasai were absorbed by neighboring ethnic groups that were traditionally cultivators. In more recent times, households that lose their herds and are unable to restock to a level sufficient to remain mobile often become permanent residents of the small towns that have grown up in pastoral areas. There seems to exist a minimum, nontrivial herd size necessary for trekking herders to survive off the herd's flow of blood and milk. That minimum of 8-12 cattle (Lybbert et al. 2001) arises because indigenous breeds' lactation rates are relatively low and multiple herders are required to supervise and guard a herd.
} 
among east African pastoralists the very poor are commonly abandoned, left to turn to begging, prostitution, and illicit drug and alcohol trade in grim rangeland towns (Little et al. 2001). Not only are transfers very often regressive, as documented earlier, but even progressive transfers from richer households to poorer ones appear to benefit primarily a "lower middle class" within the population. This pattern is evident in a broader, global history of pastoral cultures routinely sloughing off their weakest members.

A key distinguishing feature of wealth transfers among pastoralists is that they seem to occur almost exclusively within groups defined by some social identity, commonly clan or ethnicity. McPeak (2001a) reports that $93 \%$ of transfers in his data occurred between individuals who had a mother's side, father's side or an in-law relationship. Most transfers took place within an ongoing relationship between giver and receiver; $61 \%$ were to individuals from whom animals had been received in the past, and $72 \%$ were to individuals to whom animals had been previously given. Transfers among pastoralists are clearly socially embedded behaviors, which naturally leads to the conjecture that they represent a form of social insurance.

Unfortunately, the informal insurance argument - the notion that transfers represent compensatory payments for idiosyncratic shocks among herders - likewise does not seem to offer a compelling explanation of the transfer patterns observed among contemporary pastoralists in east Africa. While there is indeed evidence that transfers respond to herd losses, recent econometric studies find that the flows involved are very small in relation to the losses suffered. Lybbert et al. (2001) find that Boran pastoralists in southern Ethiopia receive, on average, a gift or loan of only one head of cattle for every thirty they lose to mortality. McPeak (2001a) finds that richer and poorer households must lose the equivalent of 84 and 234 goats, respectively, to receive the equivalent of one goat net transfer into their herd. ${ }^{4}$ Furthermore, herders report that it commonly takes months or even years before an initial request for a livestock gift or loan induces a transfer. The compensation proportions and lags found in these recent studies suggest that

\footnotetext{
${ }^{4}$ These econometric findings control for rainfall and other covariate shocks and therefore truly reflect claims rates in response to idiosyncratic shocks.
} 
interhousehold stock transfers among pastoralists offer terribly meager insurance against asset loss. This calls into question the completeness of insurance motives as an explanation for transfers in this setting.

These recent econometric findings stand in contrast to earlier, ethnographic studies that reported significant reciprocal transfers of livestock between households. The contrast between the older anthropological literature that reports considerable transfers and the newer economic literature that finds limited transfers in the same region also corroborates informal reports one hears within pastoralist communities that transfers have declined over time.

One's explanation for why transfers seem to have declined depends fundamentally on how one understands individuals' motivation to make such transfers at all. If one adopts a moral economy view of transfers as reflecting virtues inherent to a culture, then declining transfers signal moral decay. One frequently hears such claims today in east Africa. If one instead subscribes to the view that transfers are largely born of self-interested behavior, then changing transfer volumes merely reflect changes in incentives created by the environment within which individuals make such choices.

We can identify several key changes that could have induced the apparently sharp decrease in self-interested transfers behavior. Since the droughts of the early 1970's, the provision of food aid to pastoral areas has become increasingly frequent. Small towns have sprung up around relief distribution sites in the ASAL. Over the past three years in the six northern Kenyan sites in which we work, no effort has been made at targeting households. Instead, identical food aid packages are given to all residents who request them and more than 95 percent of households receive food aid every period. So there is basically a lump sum payment made to all those living in and around settlements.

Another important change relates to the growing and now relatively high level of violence in the rangelands. Livestock raiding between ethnic groups has long been a feature of 
pastoral areas (Fukui and Turton 1979, Bollig 1992, Markakis 1993, Hendrickson et al. 1996). ${ }^{5}$ However, over the past thirty years, the growth in ownership of small arms has made traditional conflicts over pasture, water, and livestock increasingly lethal as civil strife in Ethiopia, Somalia, Sudan, and Uganda has created an abundant supply of automatic weapons at low prices (Oba 1992, Hussein et al. 1999, Swift and Kraatli 1999, Osamba 2000, Smith et al.2001). ${ }^{6}$ Government security forces rarely are able to stop these conflicts in extensive grazing lands. Whether due to lack of manpower, supplies, or interest, they more commonly concern themselves with security issues in and around the small towns where they are posted. Government provided security is largely a matter of protecting town dwellers, while those who are still nomadic are left to defend themselves as best as they can.

The third key change is that pastoralist mobility is widely perceived to have deteriorated over the past generation or so due to loss of spatial refugia to expanding rangeland towns, to extensification of rainfed crop cultivation into traditional dry season grazing areas, to recently gazetted parks and protected areas, and to violently contested no-man's-lands (Coppock 1994, Desta 1999, Fleisher 1999, Heald 1999). Mobility is key to wealth accumulation and conservation in the ASAL (Little 1994, McPeak and Barrett 2001) because microclimatic variability, soil and altitude differences, and uneven spatial distribution of animals give rise to patchy and time varying rangeland carrying capacity and productivity (Behnke et al 1993, Ellis and Swift 1998).

Social identity matters as well to resource access and has become more fixed over time with the emergence of permanent town settlements. Much open rangeland and many watering points continue either unmanaged (open access) or governed by overlapping, "fuzzy" property rights (Goodhue and McCarthy 1999). These areas are typically contested by multiple social

\footnotetext{
${ }^{5}$ Cattle raiding and its attendant violence are occasionally inter-clan within some ethnic groups as well. In this paper, for the sake of clarity, we oversimplify in assuming violence is solely between ethnic groups. ${ }^{6}$ For example, the February 9, 2001, edition of the [Nairobi] Daily Nation (Muiruri 2001) reported on a raid in the Selolevi area at the borders of Isiolo, Marsabit and Samburu Districts by Samburu bandits armed with AK-47 assault rifles and sub-machine guns. The bandits killed thirty Boran herdsmen and made off with an estimated 15,000 head of cattle they had trekked to this more dangerous area in search of water and pasture following a prolonged period of drought around their base encampments to the northeast.
} 
groups. Other, common property areas surrounding the towns are, by contrast, generally

available only to members of a particular ethnic group or clan.

These changing conditions have led to a division in pastoral societies. Households who are able to maintain large enough herds to ensure mobility continue to migrate throughout the extensive grazing lands of the ASAL of east Africa. They are able to survive off of livestock products away from the small towns that have grown up in the area. These transhumant herders band together for self defense in insecure areas, thus providing their own security in a hostile environment.

In contrast, a growing population of former nomads has permanently settled in and around small towns. These households no longer have a herd that is large enough to survive on in the extensive grazing lands, and seem unable to reestablish one through livestock transfers or market-mediated restocking (Little et al. 2001, Lybbert et al. 2001, McPeak and Barrett 2001, McPeak and Little forthcoming). They therefore remain in the settled area, relying on perhaps a small herd or petty trade to provide some income, or, most troubling, becoming reliant on humanitarian relief or dangerous, illicit activities (Nduma et al 2001, Little et al 2001). The pressure of these settlements on the fragile resource base around these towns has also led to a pattern of localized degradation that further diminishes the productivity of the livestock held by the town-based poor (Schwartz et al 1991, McPeak 2001b). ${ }^{7}$ The prospects for town dwellers that have lost their herds are therefore often bleak, and have been described by various authors as a "poverty trap" (Schlee, O’Leary 1987, Legesse, Little et al. 2001). Legesse argues that the nature of poverty differs between these town dwellers and the nomadic population. He writes (p. 273)

“...For a few years after the long drought, many nomadic families continued to live a marginal existence depending on very small herds, on livestock loans, and on daily gifts of food from friends and kinsmen. They experienced seasonal hunger and sometimes had to supplement their nomadic income with income obtained by herding the stock of wealthier families and

\footnotetext{
${ }^{7}$ The use of woody resources for construction of houses, fencing, and for fuelwood decreases tree cover, while the localized grazing pressure of town-based livestock further damages rangeland productivity.
} 
urban merchants. In short, there is a form of rural poverty among the nomads, which is far less visible than the poverty of the peri-urban squatters. The two forms of poverty, however, are sharply different because the stigma that is associated with the latter is absent in the former. The nomads do not view poverty as a state of being but as an acquired trait. One does not become poor, one catches poverty, like a cold. Everybody has, at one time or another, caught this particular ailment" (italics in original).

Nathan et al. (1997) provide anthropometric evidence that supports this view; children of town dwellers are demonstrably worse off than the children of nomads.

In the following section, we develop a model that captures and explains many of the facts just reported. We illustrate the interconnectedness of herd mobility, herd size, and transfers and show how the localized provision of relief food and security can influence these relationships. This permits explanation of both the apparently striking change over time in transfer behavior among pastoralists and the current observed transfer patterns that appear consistent with neither prevailing economic theories of altruistic preferences nor of social insurance and reciprocity.

\section{A Model of Individual Migration Choice}

The analysis in this section focuses solely on a single agent's binary decision over whether to migrate his herd or not and aims at elucidating the differential and conditional impacts of migration determinants. This analysis is partly for its own sake, as it helps explain some stylized facts about pastoralism and apparent changes in the rangelands. It is also foundational, for in section 4 we will generalize these behaviors to allow for the simultaneous, strategically interdependent behaviors of multiple agents and allow the propositions with respect to migration derived in this section to inform our understanding of the evolution of interhousehold transfers among east African pastoralists.

The essence of the model we present is that there exist two externalities, an appropriation externality associated with potential site-specific overgrazing - the classic "tragedy of the 
commons" effect - and a physical security externality reflecting "strength in numbers" effects vis-à-vis hostile common opponents. Which of these effects dominates in a given setting depends on herd sizes across agents in different ethnic groups, the level of external transfers available, and prevailing ecological conditions on the range. As we will show in section 4, when the public security externality dominates, some modestly wealthier agents may be willing to make limited strategic asset transfers to somewhat poorer kinfolk in order to induce allies to migrate with them to a potentially dangerous location. When the appropriation externality dominates, some poorer folk may be willing to transfer wealth to slightly richer (but still poor) kin in order to induce them to migrate away and thereby relieve pressures on the common property grazing area. These patterns give rise to precisely the sorts of current transfer patterns reported in the previous section, and can explain the shift over time that seems to have taken place in pastoralists' interhousehold transfer behavior. This framework is likewise consistent with the common sociological observation that individuals sharing a common identity frequently appear as allies in one setting (e.g., when faced with a common adversary) and as competitors in other domains (e.g., over scarce forage and water for their herds).

We structure the model in such a way as to underscore that neither insurance nor altruism could motivate the transfers that endogenously result. The agents in our model are purely materially self-interested, so altruism plays no role; there are not even opportunities for selfinterested "warm glow" effects from giving. Also, ours is a static model, so insurance contracts cannot exist because they would be reneged upon in equilibrium. We use this structure not because we do not believe that altruism or insurance are factors in the complex reality of east African pastoralism, but rather to isolate this new mechanism we model, which seems to offer a conceptual reconciliation with the empirical evidence on east African pastoralists that extant models of transfers fail to provide.

\section{a. The agents and locations}


Consider a two-area setting (respectively, a base camp near an established settlement, B, and a satellite area, S). Define the livestock carrying capacity of each area $a \epsilon_{\{B, S\}}$, denoted $L_{a}{ }^{\max }\left(R F_{a}\right)$, as the maximal number of animals that can be placed on that plot without causing a decline in its productive potential. Carrying capacity is increasing in the stochastic rainfall realizations on an area, $R F_{a}$. Rainfall is drawn from a normal distribution with parameters $N\left(\mu_{a}, \sigma_{a}{ }^{2}\right)$. Area-specific per animal productivity, ${ }^{8} \mathrm{f}_{\mathrm{a}}\left(R F_{a}\right) \epsilon[0, \infty]$, is increasing in realized rainfall. Satellite areas have higher intrinsic productivity than base areas, $\mathrm{f}_{\mathrm{s}}(R F)>\mathrm{f}_{\mathrm{b}}(R F)$ for identical rainfall, and the rainfall distribution in the satellite area first-order stochastically dominates that in the base area. Hence, herds' unconditional expected productivity is strictly higher in the satellite area than at the base area. For the same ecological reasons that productivity is higher there, satellite area carrying capacity exceeds base area carrying capacity for identical rainfall realizations, $L_{s,}{ }^{\max }(R F)>$ $L_{, b}{ }^{\max }(R F)$.

Let there be three different herders representing two different, mutually hostile ethnic groups. Herders $i$ and $j$ share a common ethnic identity and are thus allies in any inter-ethnic conflict; $k$ hails from the rival group. The herd size distribution $\left\{\mathrm{L}^{\mathrm{i}}, \mathrm{L}^{\mathrm{j}}, \mathrm{L}^{\mathrm{k}}\right\}$ is common knowledge. Each herder makes a discrete decision whether or not to migrate from his base camp area to the satellite area $\left(\mathrm{m}=1\right.$ for migration, 0 otherwise). ${ }^{9}$ No pastoralist ever migrates to the base camp area of another ethnic group, so inter-ethnic resource competition is purely in the satellite area. For the remainder of this section we study herder $i$ 's migration choice, $m^{i}$, conditional on the migration choices of the others, $m^{j}$ and $m^{k}$, so as to be able to focus on the determinants of pastoralist migration. In the next section we relax this exogeneity assumption and explore the strategically interdependent migration decisions of the three herders and the distributionconditional transfer regime that results endogenously.

\footnotetext{
${ }^{8}$ Productivity here reflects the production of consumption goods: milk, blood and meat.

${ }^{9}$ We assume that no herder can be prohibited from moving by other members of his clan. If multiple herders each choose to move from one site to another, they necessarily do so together.
} 


\section{b. Appropriation and security externalities}

When the number of animals occupying an area exceeds its variable carrying capacity, productivity-degrading overgrazing results. When resource competition is excessive, an appropriation externality results, wherein one herder's migration choice affects the productivity of other herders' animals. The herders (sharing a common identity) in the base area thus become competitors. Let $\delta_{a}=\left(L_{a}^{i}+L_{a}^{j}+L_{a}^{k}\right) / L_{a}{ }^{\max }\left(R F_{a}\right)$ express the area-specific occupancy rate as a proportion of its rainfall-dependent carrying capacity. ${ }^{10}$ Then we can define the expected proportional productivity loss due to the appropriation externality as $\eta_{a}\left(L_{a}^{i}, L_{a}^{j}, L_{a}^{k}, R F_{a}\right)=\left(\delta_{a}-1\right) / \delta_{a}$ if $\delta_{a} \geq 1$ and $\eta_{a}=0$ if $\delta_{a}<1$. This implies that herder $i$ 's expected productivity loss at the satellite area is weakly increasing in other herders' migration decisions, $\partial \eta_{S} / \partial \mathrm{m}^{\mathrm{j}}, \partial \eta_{S} / \partial \mathrm{m}^{\mathrm{k}} \geq 0$. Of course, herder $i$ 's expected productivity loss at the base area is also weakly decreasing in his kinsman's migration decision, $\partial \eta_{B} / \partial \mathrm{m}^{\mathrm{j}} \leq 0$.

Other herders' migration decisions matter for another reason as well. If herders $i$ and $k$ both migrate to the satellite area, then there is a positive probability that conflict will erupt, leading to a loss of animals. This risk of raiding and violence arises only when pastoralists who belong to a different social group jointly occupy a single area. ${ }^{11}$ Pastoralists of a same social group will never raid or act violently against each other. Rather, there is strength in numbers in the sense that the presence of another member of a herder's ethnic group reduces his expected losses due to raiding and violence through a security externality Hence, a common identity in the satellite area makes pastoralists allies. Denote this risk, again expressed as an expected proportional per animal productivity loss, as $\Phi\left(\theta L_{s}^{i} /\left(L_{s}^{i}+L_{s}^{j}\right)\right) m^{k}$, where $\Phi($.$) is some density$

\footnotetext{
${ }^{10}$ Note that by construction, $L_{B}^{k}$ equals zero.

${ }^{11}$ Today, violence and raiding risk only exist in the satellite areas of the hinterland. The town-based provision of public security services in the form of police protection provides reasonable assurance against raiding losses around towns; we simplify this to perfect assurance in the model. Prior to the introduction of town-based public services a few generations ago, however, there was no practical distinction between base and satellite areas, so more land was contested and raiding threats were nearly omnipresent.
} 
function defined over the closed interval $[0,1]$ with $\Phi(0)=0 .{ }^{12}$ If the rival pastoralist does not migrate, $m^{k}=0$, then there is zero expected loss. The base camp area always enjoys zero expected loss since rival groups do not try to occupy the common property lands of another group. If herder $k$ does migrate, then $i$ 's expected loss is increasing in the universally known exogenous violence probability parameter, $\theta$, and in $i$ 's share of his ethnic group's livestock on the contested terrain. The implication is that a rise in the number of livestock migrating from the same social group creates a public good security externality.

An important trade-off now emerges. On the one hand, if $i$ and $j$ both migrate, then the presence of more pastoralists from $i$ 's ethnic group creates a positive security externality against raiding if and only if $k$ also moves to the satellite area. On the other hand, it also generates a negative resource appropriation externality if and only if the resulting occupancy rate exceeds the area's carrying capacity. As the next section demonstrates, this tradeoff creates a limited space in which either distributionally progressive livestock transfers from richer herders to poorer ones or distributionally regressive transfers between the ex ante poor are both equilibrium outcomes of the simultaneous choice of the three herders under particular combinations of ecological conditions, ex ante herd distributions, external transfer volumes, and the exogenous probability of violence. But before we get to that analysis, let us study the migration choice a bit further, for it yields interesting insights as well as building blocks toward our analysis of interhousehold transfers.

\section{c. Exogenous transfers and movement costs}

As mentioned in section 2, food aid has become nearly ubiquitous in the rangeland towns of the East African ASAL. We incorporate this important feature through the introduction of an exogenous transfer from outside the system, $\tau$, which pastoralists only receive if they are at base

\footnotetext{
${ }^{12}$ Since security critically depends on human labor rather than herd size, our model implicitly assumes that the treks are made in fixed proportions herder/herd size.
} 
camp, where they have ready access to town-based distribution of relief food. ${ }^{13}$ This geography of food aid distribution creates a fixed cost to migration. ${ }^{14}$ If a pastoralist chooses to leave the base camp for higher expected productivity satellite areas, he faces a fixed opportunity cost of $\tau$. In addition to this fixed cost of foregone food aid, the migrating pastoralist incurs variable movement costs, $m c\left(L^{i}\right)$, that are monotonically increasing and concave in herd size, and $m c(0)=$ 0 . This cost reflects the animal weight loss and risk of injury or loss to wild predators incurred on the migratory trek.

Production is increasing in area-specific growth potential and actual rainfall. The common property appropriation externality negatively affects the production function only when the area-specific carrying capacity is exceeded. In the absence of the common property externality, the pastoralist's production is unambiguously increasing in individual herd size.

\section{d. The pastoralist's migration choice}

We assume pastoralists maximize expected income conditional on others' simultaneous choices $\left(m^{j}, m^{k}\right)$ that affect payoffs. Utility is assumed to be increasing in income. The choice problem facing pastoralist $i$ is thus

$$
\begin{aligned}
& \underset{m^{i} \in\{0,1\}}{\operatorname{Max}} E\left(Y^{i}\right) \\
& Y^{i} \equiv m^{i}\left\{\left(1-\eta_{S}\right)\left(1-m^{k} \Phi\left(\theta \frac{L^{i}}{L^{i}+m^{j} L^{j}}\right)\right) L^{i} f_{S}\left(R F_{S}\right)-m c\left(L^{i}\right)\right\}+\left(1-m^{i}\right)\left\{\left(1-\eta_{B}\right) L^{i} f_{B}\left(R F_{B}\right)+\tau\right\}
\end{aligned}
$$

\footnotetext{
${ }^{13}$ Recall from section 2 that food aid distribution in the region is typically independent of a pastoralists' wealth, so we treat this as a lump sum that is identical for all pastoralists. Our assumption that food aid is available only in the base camp is an obvious oversimplification. The key feature is that leaving the satellite area to come to town to receive food aid entails a nontrivial fixed cost. For simplicity's sake, we model this cost as prohibitive.

${ }^{14}$ There are, of course, prospective benefits to being near town other than just receipt of food aid and police protection: access to markets and a thus a wider variety of consumer goods, more timely information from the outside world, etc. These other location-specific amenities merely reinforce the basic logic of our model, however, that the rise of localized provision of public services change the dynamics of a wide range of human behavior, including migration and transfer patterns.
} 
The first term represents pastoralist $i$ 's payoff associated with a choice of migrating to the satellite area, whereas the second term captures his payoff when staying at the base area. Both terms include an expression for the pastoralist's effective herd productivity, defined as his ex ante herd size adjusted for the expected impacts of the appropriation and security externalities and multiplied by the site-specific per animal productivity. Let us label this gross total product $\mathrm{P}_{a}$, with

(2) $P_{S} \equiv\left(1-\eta_{S}\right)\left(1-m^{k} \Phi\left(\theta \frac{L^{i}}{L^{i}+m^{j} L^{j}}\right)\right) L^{i} f_{S}\left(R F_{S}\right)$ and

(3) $P_{B} \equiv\left(1-\eta_{B}\right) L^{i} f_{B}\left(R F_{B}\right)$.

Pastoralist $i$ then rationally decides to move to the satellite camp $\left(m^{i}=1\right)$ if and only if he expects to reap at least as high or higher net benefits from doing so relative to staying at the base camp $\left(m^{i}=0\right)$. This logic yields the movement decision rule that pastoralist $i$ chooses $m^{i}=1$ if and only if:

(4) $\left(1-\eta_{S}\right)\left(1-m^{k} \Phi_{S}\left(\theta \frac{L^{i}}{L^{i}+m^{j} L^{j}}\right)\right) L^{i} f_{S}\left(R F_{S}\right)-m c\left(L^{i}\right) \geq\left(1-\eta_{B}\right) L^{i} f_{B}\left(R F_{B}\right)+\tau$

Rearranging the terms and dividing both sides of the inequality by $L^{i}$ gives rise to the following necessary and sufficient migration condition:

(5) $f_{S}\left(R F_{S}\right)-f_{B}\left(R F_{B}\right) \geq f_{S}\left(R F_{S}\right)\left\{\eta_{S}+m^{k} \Phi\left(\theta \frac{L^{i}}{L^{i}+m^{j} L^{j}}\right)\left(1-\eta_{S}\right)\right\}-f_{B}\left(R F_{B}\right)\left\{\eta_{B}\right\}+\frac{\tau}{L^{i}}+\frac{m c\left(L^{i}\right)}{L^{i}}$

The lefthand side of expression (5) is independent of any herders' individual characteristics or choices. It reflects solely the biophysically determined productivity differential between the two grazing areas in which the pastoralist might graze his herd. In expectation, this difference is always positive because range conditions in the satellite areas first order stochastically dominate those in the base camp areas. As such, this value reflects a measure of general migration appeal, common for all pastoralists facing the same locational choice options.

By contrast, each term on the righthand side of expression (5) is individual-specific, partially determined by agent $i$ 's individual herd size. Call the righthand side of (5) $\Omega$. The first 
two terms of $\Omega$ each include an area-specific production function multiplied by a sub-unit coefficient. The value of the lefthand side always exceeds the difference between the first two terms of $\Omega$. As a consequence, the migration condition is satisfied as long as the third and fourth righthand side terms are sufficiently small. This underscores how point-based free food aid distribution discourages migration, leading to increased herd concentration in base camp areas, an observation borne out empirically in the region (McPeak 2001b). More generally, however, the returns to migration depend fundamentally on $\mathrm{m}^{\mathrm{j}}, \mathrm{m}^{\mathrm{k}}, \theta$ and $\tau$.

As shown in Figure 1, the site-specific productivity differences give steeper slope to $P_{s}$ than to $\mathrm{P}_{\mathrm{B}}$, as long as the probability of livestock raiding and conflict is sufficiently small. More formally, the necessary condition underlying the graphical representation in Figure 1 is:

(6) $m^{k} \Phi\left(\theta \frac{L^{i}}{L^{i}+m^{j} L^{j}}\right)<1-\frac{\left(1-\eta_{B}\right) f_{B}\left(R F_{B}\right)}{\left(1-\eta_{S}\right) f_{S}\left(R F_{S}\right)}$

The ratio on the righthand side of the above inequality is necessarily smaller than one. Our subsequent analysis assumes that the site-specific differences are such that the above condition is satisfied for any possible value for the risk of raiding or violence. ${ }^{15}$ In the absence of site-specific lump sum food aid transfers and variable movement costs, all pastoralists would move, as they did generations ago. But those costs of moving induce pastoralists with smaller herds to choose to stay at base camp and suffer lower productivity. $\mathrm{P}_{\mathrm{S}}$ therefore single crosses $\mathrm{P}_{\mathrm{B}}+\tau$ from below, and once the difference between the two productivity functions at least equals $m c\left(L^{i}\right)$, then the pastoralist optimally chooses to migrate, creating an observed productivity function that is convex in wealth even though the site-specific production technologies are strictly concave. ${ }^{16}$

Define the individual-specific migration threshold, $L^{i^{*}}$, as the minimum herd size necessary to make migration to the satellite area preferable. ${ }^{17}$ Each particular combination of parameter values, production functions and migration strategies chosen by the other herders

\footnotetext{
${ }^{15}$ Note that in the absence of livestock raiding or violence, the slope of $P_{S}$ necessarily surpasses that of $P_{B}$. ${ }^{16}$ In this regard, there is some similarity to the occupational choice model of Banerjee and Newman (1993).

${ }^{17} \mathrm{~L}^{\mathrm{i} *}$ is the individual-specific threshold herd size which sets the lefthand side of equation (5) equal to the righthand side. Let us denote the righthand side of equation (5) that defines the migration threshold (ie. equation (5) holds with equality) as $\Omega$ '.
} 
affects the migration threshold. For any given combination, however, this specification generates a monotone, piecewise concave income function that is globally convex in herd size, with a kink point at $L^{i^{*}}$ (Figure 2). The threshold effect implies that below $L^{i^{*}}$, pastoralists find themselves in a low-level equilibrium of the sort described for this region empirically by Lybbert et al. (2001) and McPeak and Barrett (2001).

We now wish to identify how this migration threshold changes with marginal changes in a number of parameter values. An increase in $i$ 's ex ante herd size affects the likelihood that he opts to migrate. Wealthier pastoralists are more likely to migrate to the satellite area if and only if (7)

$$
\begin{aligned}
& \frac{\partial \Omega}{\partial L^{i}} \leq 0 \\
& \Leftrightarrow \\
& f_{S}\left(R F_{S}\right)\left\{\frac{\partial \eta_{s}}{\partial L^{i}}\left(1-m^{k} \Phi\left(\frac{L^{i}}{L^{i}+m^{j} L^{j}}\right)\right)+m^{k} \frac{\partial \Phi}{\partial L^{i}}\left(1-\eta_{s}\right)\right\}-f_{B}\left(R F_{B}\right) \frac{\partial \eta_{B}}{\partial L^{i}} \leq \frac{\tau+m c\left(L^{i}\right)-m c^{\prime} L^{i}}{L^{i^{2}}}
\end{aligned}
$$

Given our earlier specification of the variable movement costs function, the righthand side of the inequality is necessarily positive and increasing in the size of food aid transfers and the degree of concavity of the variable movement cost function. In other words, a marginal increase in individual herd size is more likely to trigger migration to the satellite area if the induced reduction in average total migration costs is sufficiently high. ${ }^{18}$

The two terms on the lefthand side of the inequality correspond with the productivity losses induced by an incremental change in individual herd size respectively at satellite and base area. At the base area, a rise in individual herd size (weakly) negatively impacts the individual's production outcome solely through its effect on the area-specific appropriation externality. At the satellite area, a marginal change in individual wealth generates an additional indirect effect on the pastoralist's production outcome, namely via a change in the individual's security externality. Wealthier individuals are more likely to move to the satellite area if the difference in expected production losses across base and satellite area is sufficiently great, favoring a move to the

\footnotetext{
${ }^{18}$ Formally, the righthand side of condition (7) is identical to the negative of the derivative of $\left(\tau / \mathrm{L}^{\mathrm{i}}+\right.$ $\left.\mathrm{mc}\left(\mathrm{L}^{\mathrm{i}}\right) / \mathrm{L}^{\mathrm{i}}\right)$ with respect to $\mathrm{L}^{\mathrm{i}}$.
} 
satellite area. In the case where following a marginal increase in individual herd size, the new occupancy rates at both areas still lie below their respective capacity stocking rates, the weak inequality is necessarily satisfied for sufficiently small induced changes in the risk of raiding at satellite area. This leads to our first proposition.

Proposition 1: A larger individual herd increases the probability that the individual's migration condition is fulfilled as the gap between the induced production losses across base and satellite area increases and as the marginal migration costs decrease.

We now impose a necessary condition that ensures a marginal rise in an individual's herd always induces a rise in the probability that he will migrate to the satellite area. Ceteris paribus, wealthier pastoralists are more likely to migrate to the satellite area only if

(8) $f_{S}\left(R F_{S}\right)\left\{\left(\frac{\partial \eta_{S}}{\partial L^{i}}+m^{k} \frac{\partial \phi}{\partial L^{i}}\right)-\left(m^{k} \phi \frac{\partial \eta_{S}}{\partial L^{i}}+\eta_{S^{\prime}} m^{k} \frac{\partial \phi}{\partial L^{i}}\right)\right\}<\left(\frac{\tau+m c\left(L^{i}\right)-m c^{\prime} L^{i}}{L^{i^{2}}}\right)+f_{B}\left(R F_{B}\right) \frac{\partial \eta_{B}}{\partial L^{i}}$

If a marginal rise in individual herd size leaves the satellite appropriation externality unchanged and the risk of raiding is absent $\left(m^{k}=0\right)$, then the above inequality always holds. On this basis, we make the following assumption so that the model corresponds with the empirical regularities of east African pastoralists.

Assumption 1: Heterogeneity across rangeland carrying capacities are such that, together with sufficiently high marginal changes in migration costs in response to herd size changes, wealthier pastoralists are ceteris paribus more likely to migrate than poorer pastoralists.

We are also interested in understanding how an increase in wealth of a (non)migrating ally influences one's incentive to migrate. Two cases are separately considered: $m^{j}=1$ and $m^{j}=0$. Making use of the Implicit Function Theorem, we can rewrite the marginal effect of herd size owned by one's clansman on the individual's migration threshold as: 
(9) $\frac{\partial L^{i^{*}}}{\partial L^{j}}=-\frac{\partial \Omega^{\prime} / \partial L^{j}}{\partial \Omega^{\prime} / \partial L^{i^{*}}}$

In the case of $m^{j}=1$, the numerator of (9) takes the form

$$
\frac{\partial \Omega^{\prime}}{\partial L^{j}}=f_{S}\left(R F_{S}\right)\left\{\frac{\partial \eta_{s}}{\partial L^{j}}\left(1-m^{k} \Phi\left(\frac{L^{i}}{L^{i}+L^{j}}\right)\right)+m^{k} \frac{\partial \Phi}{\partial L^{j}}\left(1-\eta_{s}\right)\right\}
$$

while the denominator is

(11) $-\frac{\partial \Omega^{\prime}}{\partial L^{i^{*}}}>0$

Given assumption 1, the denominator is strictly positive. It is now useful to introduce the notions of strategic complementarity and strategic substitutability. If in response to a marginal increase in $j$ 's herd size at the satellite area, pastoralist $i$ is more likely to migrate to the satellite area, then the migration decisions of both pastoralists are defined as strategic complements. Mathematically, strategic complementarity requires that

$$
\left\{\frac{\partial \eta_{s}}{\partial L^{j}}\left(1-m^{k} \Phi\left(\frac{L^{i}}{L^{i}+L^{j}}\right)\right)+m^{k} \frac{\partial \Phi}{\partial L^{j}}\left(1-\eta_{s}\right)\right\}<0
$$

$(12) \Leftrightarrow$

$$
\left|m^{k} \frac{\partial \Phi}{\partial L^{j}}\left(1-\eta_{s}\right)\right|>\frac{\partial \eta_{s}}{\partial L^{j}}\left(1-m^{k} \Phi\left(\frac{L^{i}}{L^{i}+L^{j}}\right)\right)
$$

In words, the positive security externality effect generated by an increase in pastoralist $j$ 's wealth $\left(\partial \Phi / \partial \mathrm{L}^{j}\right)$ must be sufficiently high to outweigh the inextricable nonpositive appropriation externality effect. Clearly, if the rangeland conditions at the satellite area are such that the new occupancy rate still lies below its carrying capacity, then the requirement for strategic complementarity will unambiguously hold. In that case, a marginal rise in wealth of pastoralist $j$ generates only a positive public goods security externality, enhancing pastoralist $i$ 's expected 
benefits from migrating. Conversely, in the absence of the risk of livestock raiding $\left(m^{k}=0\right)$, the requirement for strategic complementarity will never be satisfied.

The corollary is that the migration choices of pastoralist $i$ and $j$ constitute strategic substitutes if a marginal increase in pastoralist $j$ 's wealth induces an upward shift in pastoralist $i$ 's migration threshold. Mathematically, this situation emerges when

$$
\left\{\frac{\partial \eta_{s}}{\partial L^{j}}\left(1-m^{k} \Phi\left(\frac{L^{i}}{L^{i}+L^{j}}\right)\right)+m^{k} \frac{\partial \Phi}{\partial L^{j}}\left(1-\eta_{s}\right)\right\} \geq 0
$$

$(13) \Leftrightarrow$

$$
\left|m^{k} \frac{\partial \Phi}{\partial L^{j}}\left(1-\eta_{s}\right)\right| \leq \frac{\partial \eta_{s}}{\partial L^{j}}\left(1-m^{k} \Phi\left(\frac{L^{i}}{L^{i}+L^{j}}\right)\right)
$$

This expression formalizes the case wherein an incremental rise in the herd size owned by the migrating ally reduces pastoralist $i$ 's incentive to migrate, all other things held equal. This holds when the induced negative appropriation externality outweighs the positive security externality effect in the satellite area.

In the case of $m^{j}=0$, the numerator of (9) becomes

$$
\frac{\partial \Omega^{\prime}}{\partial L^{j}}=-f_{B}\left(R F_{B}\right)\left\{\frac{\partial \eta_{B}}{\partial L^{j}}\right\} \leq 0
$$

while the denominator is

$$
\text { (15) }-\frac{\partial \Omega^{\prime}}{\partial L^{*}}>0
$$

The concepts of strategic substitutability and complementarity apply in this context as well, but now as they relate to the base camp area and the decision not to migrate $\left(m^{j}=0\right)$. When a marginal increase in wealth of a non-migrating pastoralist $j$ lowers pastoralist $i$ 's migration threshold, thereby encouraging him to vacate the base area and dispersing the ethnic group across space, their migration strategy choices are conceived to constitute strategic substitutes. The case of strategic complementarity never arises with $m^{j}=0$ because there is no security externality in the 
base camp, only a nonpositive appropriation externality. Hence, with $m^{j}=0$, a rise in the number of cattle owned by herder $j$ at the base area therefore either causes a downward shift in herder $i$ 's migration threshold or leaves the threshold unaffected. The latter case holds if, despite the increase in the occupancy rate at the base area, the base area's carrying capacity remains unsurpassed. These findings lead to our second proposition.

Proposition 2: A marginal increase in the herd size of a migrating pastoralist $j$ lowers pastoralist i's migration threshold if and only if the induced positive security externality effect outweighs the parallel negative appropriation externality effect. A marginal increase in the herd size of a non-migrating pastoralist $j$ never raises pastoralist $i$ 's migration threshold.

Change in external food aid transfers likewise affect pastoralist $i$ 's migration behavior. By similar use of the Implicit Function Theorem, one can readily establish that a rise in food aid transfers unambiguously increases pastoralist $i$ 's migration threshold by increasing the fixed cost of migration. ${ }^{19}$ As a consequence, the required minimal herd size to make migration attractive increases in the level of freely available food transfers.

Proposition 3: An increase in the total amount of freely available transfers raises pastoralist i's migration threshold.

If pastoralist $k$ chooses not to migrate from his own base camp area, then there is no risk of conflict and therefore no security externality between pastoralists $i$ and $j$. The only relevant case to check is therefore where $m^{k}=1$. A marginal rise in pastoralist $k$ 's herd size (weakly) increases pastoralist $i$ 's migration threshold. From $i$ 's perspective, migration loses appeal because of the

\footnotetext{
${ }^{19}$ In the interests of brevity, we omit the proof. A formal proof of this and other omitted (but we believe straightforward) claims to follow, all using the same Implicit Function Theorem technique that led to Proposition 2, are available on request from the authors.
} 
heightened probability of raiding, a potential appropriation externality, or both if pastoralist $k$ herds more animals at the satellite area.

Proposition 4: If pastoralist $k$ stays at his base area $\left(m^{k}=0\right)$, then his herd size does not affect pastoralist i's migration threshold. Otherwise, pastoralist i's migration threshold is increasing in pastoralist $k$ 's herd size.

Rainfall obviously influences pastoralist $i$ 's equilibrium migration strategy. Different assumptions about the correlation between the rainfall distributions at base and satellite area will generate different insights. In the event of increased rainfall in the satellite area, holding base area rainfall constant, then pastoralist $i$ 's migration threshold necessarily falls because productivity away improves. A marginal increase in rainfall also increases the carrying capacity of the satellite area, possibly reducing $\eta_{S}$ and thereby creating further productivity gains, as shown in equation $(16) .^{20}$

(16) $\frac{\partial \Omega}{\partial R F_{S}}=\frac{\partial f_{S}}{\partial R F_{S}}\left\{\eta_{S}+m^{k} \phi\left(\theta \frac{L^{i}}{L^{i}+m^{j} L^{j}}\right)\left(1-\eta_{S}\right)\right\}+f_{S}\left\{\frac{\partial \eta_{S}}{\partial R F_{S}}\left(1-m^{k} \phi\left(\theta \frac{L^{i}}{L^{i}+m^{j} L^{j}}\right)\right)\right\}$

Conversely, if rainfall increases in the base area, holding satellite area rainfall constant, pastoralist $i$ 's migration threshold similarly increases because it stimulates base area livestock productivity both directly and indirectly by potentially mitigating local appropriation externalities by increasing the base area's carrying capacity. In sum, microvariability induces pastoralists to follow the rains, migrating if it falls in the satellite area, staying if it falls around the base camp.

If the marginal change in rainfall is uniformly distributed across both the satellite and base areas, as often happens in time of drought, then this perfectly correlated incremental change increases the lefthand side of the migration condition at a decreasing rate (given first-order stochastic dominance and decreasing marginal productivity of rainfall). Rainfall also affects the

\footnotetext{
${ }^{20}$ Note that increased rainfall in the satellite area also raises the value at the lefthand side of equation (5), thus heightening the likelihood that the individual migration condition is satisfied.
} 
righthand side of pastoralist $i$ 's migration condition. Together, a marginal increase in rainfall at both satellite and base areas generates a downward shift in the pastoralist $i$ 's migration threshold.

Proposition 5: A marginal change in rainfall favoring the satellite (base) area induces a downward (upward) shift in pastoralist i's migration threshold. Pastoralist i's migration threshold falls in response to a spatially uniform change in rainfall.

The final relation we seek to establish in this section relates to change in the exogenous risk parameter, $\theta$. When $m^{k}=1$, an increase in the exogenous risk of raiding, perhaps due to the spread of modern weaponry or to increased interethnic tension due to greater resource pressure, diminishes pastoralist $i$ 's expected payoff from migrating and thus dampens his propensity to migrate. If $m^{k}=0$, then $\theta$ has no impact on $i$ 's migration choice, yielding our final proposition.

Proposition 6: With $m^{k}=1$, an increase in the exogenous risk of raiding generates an upward shift in pastoralist $i$ 's migration threshold.

The insights summarized in the six preceding propositions lay the foundation for the next section, in which we explore the transfer choice as the rational outcome of pastoralists' strategic interdependence. The risk of violence and livestock raiding and stocking rate pressures on common property rangelands can evoke a self-interested rationale for distributionally regressive or limited egalitarian transfers of the sort one seems to find in the empirical evidence on east African pastoralists and which extant theories cannot readily explain.

\section{Three-person non-cooperative migration game}


The preceding section treated the decision of pastoralist $i$ in isolation from the simultaneous, interdependent choices of the other two pastoralists so as to better understand the nature and determinants of the crucial migration choice. In this section we now treat the three pastoralists' decisions as a noncooperative game of simultaneous migration and transfer choices in order to tease out the conditions under which transfers emerge in equilibrium in the absence of altruism or repeated interactions that might permit endogenously enforceable informal insurance contracts.

The intuition of the results we develop runs as follows, building directly on the previous section's propositions. The larger an individual's herd, the greater the incentive to migrate to the satellite area, ceteris paribus. When stocking rate pressures on the open range are low or nonexistent and there is real risk of conflict with an opponent, a relatively wealthy, migrating pastoralist may then benefit from manipulating a poorer ally's independent migration choice by transferring animals to him and thereby inducing him to move voluntarily, and thus to fight alongside the bigger herder against their common foe. ${ }^{21}$ However, some pastoralists are so poor, perhaps due to an adverse, idiosyncratic shock, that the transfer necessary to induce them to migrate is excessive relative to the security externality benefits the wealthier herder would enjoy.

As a consequence, the resulting egalitarian transfers are limited in two crucial senses. First, they are limited to the transfer level necessary just to bring one's ally to his migration threshold and thereby induce him to move - and fight - alongside the donor. ${ }^{22}$ Second, they are limited only to ally households that are below but reasonably near the migration threshold anyway, so that the security externality benefits can justify the cost of the animals given away.

One outcome of this limited rational egalitarianism is that the poorest members of the ethnic group do not receive internal transfers (just external transfers of food aid), have herd sizes too small to migrate, and are consequently trapped in a relatively low productivity equilibrium.

\footnotetext{
${ }^{21}$ While one herder may try to induce another herder to accompany him in his trek to the satellite area, it is assumed that nobody has the capacity to exclude any group member from moving with him. We thus rule out the possibility that a poor herder must pay a richer ally for 'protection' during his move.

${ }^{22}$ Note that if the herder refuses to accept the transfer offered by the donor, then his outside option is to stay in the base area. Hence his threat point is defined by his expected utility from staying when the other, richer group member nevertheless prefers to move out.
} 
This gives rise to a second, distinct type of manipulative transfer. If overstocking pressures are significant around the small towns in which the poorest are trapped, some of the poor may find it in their interest to transfer an animal to a wealthier herder whose ex ante herd size lies just below his migration threshold, inducing the wealthier recipient to move and thereby increasing the productivity of the remainder of the poorer donor's herd. There thus exist state-dependent interdependencies between migration choices undertaken by pastoralists sharing a common social identity, manipulative interhousehold transfer behaviors, and low level productivity equilibria.

Without loss of generality, let $i$ be the wealthier of the two herders in the ethnic group $\left(L^{i}\right.$ $\geq L^{j}$ ). Herder $k$, who is initially located at his own base area, different from that of $i$ and $j$, may have more or less animals than either of his rivals, although the herd size distribution is common knowledge. Given the discrete, simultaneous migration decision by these three agents, in theory there exist eight different combinations of strategies that can possibly emerge. However, Proposition 1 rules out two of these possibilities because if $i$ does not choose to migrate, then neither will $j$ move because migration incentives are increasing in herd size. Figure 3 depicts the feasible strategy space of six migration/no migration combinations.

The problem, from pastoralist $i$ 's perspective, is now one of maximizing expected income subject to the independent choices of pastoralists $j$ and $k$. Each of the three herders is simultaneously solving the migration choice problem in (1). The key now is to recognize that their common social identity can create an incentive for either $i$ or $j$ to offer his fellow group member a side payment in the form of an interhousehold livestock transfer, in order to induce the other to migrate. To be more precise, $i$ 's migration choice now becomes

$$
\begin{aligned}
& \operatorname{Max}_{\beta_{i j,}, m^{i} \in\{0,1\}} E\left(Y^{i}\right) \\
& \text { (17) } Y^{i} \equiv m^{i}\left\{\left(1-\eta_{S}\right)\left(1-m^{k} \Phi\left(\frac{\theta\left(L^{i}-\beta_{i j}\right)}{\left(L^{i}-\beta_{i j}\right)+m^{j}\left(L^{j}+\beta_{i j}\right)}\right)\right)\left(L^{i}-\beta_{i j}\right) f_{S}\left(R F_{S}\right)-m c\left(L^{i}-\beta_{i j}\right)\right\} \\
& +\left(1-m^{i}\right)\left\{\left(1-\eta_{B}\right) L^{i} f_{B}\left(R F_{B}\right)+\tau\right\}
\end{aligned}
$$


where $\beta_{i j}$ is the transfer from $i$ to $j$, chosen by $i$ only if $m^{i}=1$, which is a necessary condition for strategic complementarity. ${ }^{23}$ Intuitively, $\beta_{i j}>0$ only when the transfer is necessary and sufficient to induce $j$ to migrate, an incentive compatibility constraint, and when the security benefits to $i$ of $j$ 's migration outweigh the costs of both relinquishing wealth and potentially creating or aggravating the resource appropriation externality in the satellite area, an individual rationality constraint. The latter condition is closely related to the notion of strategic complementarity defined in proposition 2. The minimum transfer necessary to induce $j$ to move will be $\beta_{i j}{ }^{m i n}=\max \left(L^{* j}{ }_{\mid m i=1}-L^{j}\right.$, 0). ${ }^{24}$ If herder $\mathrm{j}$ already owns sufficient livestock that he benefits from migrating to the satellite area irrespective of whether he is given additional animals, there is no need for $i$ to make a transfer: $\beta_{i j}{ }^{m i n}=0$. If, however, $L^{j}$ is sufficiently small that without the transfer $i$ believes that $m^{j^{*}}=0$, then a stock transfer may be in $i$ 's interests. Define $\beta_{i j}{ }^{\max }$ as the transfer level that would leave herder $i$ indifferent between making a transfer and moving to the satellite area alone. Obviously $\beta_{i j}{ }^{\max }>0$ if and only if strategic complementarity exists, i.e., if $j$ 's presence in the satellite area confers more in security benefits than it takes away through resource competition.

Put these two conditions together and equilibrium positive transfers must fall in the interval $\left[\beta_{i j}{ }^{m i n}, \beta_{i j}{ }^{m a x}\right]$. No transfers result if $\beta_{i j}{ }^{m a x}<\beta_{i j}{ }^{m i n}$ or $\beta_{i j}{ }^{m i n}=0$. This is the sense in which transfers are limited in volume and can exclude both the poorest and richest pastoralists under contemporary conditions. If the migration threshold is reasonably high, perhaps because food aid distribution is significant, carrying capacity is low and raiding risks are great, then the necessary transfer to induce $j$ 's migration may well exceed $i$ 's reservation transfer level. We conjecture that over time, the changes in the east African ASAL described in section 2 have caused $\left[\beta_{i j}{ }^{\min }, \beta_{i j}{ }^{\max }\right]$ to become an empty set in many cases, thereby explaining why significant past interhousehold transfers have fallen markedly.

\footnotetext{
${ }^{23}$ We will shortly consider the possibility of $\beta_{j i}=-\beta_{i j}$, but abstract from this for the moment.

${ }^{24}$ Note that pastoralist $j$ 's migration threshold $\left(L^{* j}{ }_{\mid m i=1}\right)$ is, like before, defined by equation (5) with equality, but now takes into account pastoralist $i$ 's reduction of own herd size following the minimal transfer.
} 
Although transfers will only occur among pastoralists of the same social identity, they need not always be distributionally progressive. If either herder is willing to migrate based on his ex ante herd size, then $\beta_{i j}>0$ is the only transfer in equilibrium. This result obtains because $i$ will always be willing to migrate when $j$ is willing to migrate, since the only difference in their choice problem is their ex ante herd size and, by proposition 1, the migration threshold is decreasing in herd size so there will be no transfers from $j$ to $i, \beta_{j i}=0$ if $L^{*_{i}}<L^{i}$. If, however, neither $i$ nor $j$ have ex ante herd sizes sufficient to justify migration, the possibility of regressive equilibrium transfers arises. The logic depends on the notion of strategic substitutes, as defined in the previous section. If herd sizes in the base camp area are sufficient to induce significant appropriation externalities and pastoralist $i$ 's herd size falls just below his migration threshold, then a livestock transfer from the poorer household, $j$, to the richer-but-still-poor household, $i$, may be mutually beneficial. ${ }^{25}$ Somewhat more formally, the minimum transfer necessary to induce $i$ to move would be $\beta_{j i}{ }^{\min }=\max \left(L^{*_{i}}{ }_{\mid m j=0}-L^{i}, 0\right)$. Now define $\beta_{j i}{ }^{m a x}$ as the transfer level that would leave herder $j$ indifferent between making a transfer intended to induce $i$ to exit the base camp common property and sharing those grazing areas in spite of the overstocking pressures. Strategic substitutability is necessary but not sufficient for $\beta_{j i}{ }^{\max }>0$, just as strategic complementarity is necessary but not sufficient for $\beta_{i j}{ }^{m a x}>0$. If the transfer necessary to induce $i$ 's migration is no greater than the maximum transfer $j$ is willing to make to have the base camp grazing area to himself, then a regressive transfer in the interval $\left[\beta_{j i}{ }^{\min }, \beta_{j i}{ }^{m a x}\right]$ takes place in equilibrium.

Finally, in equilibrium $\beta_{j k}=\beta_{i k}=0$ since increasing $k$ 's herd size only increases the likelihood that $k$ migrates to the satellite area, thereby both increasing local stocking rates and

\footnotetext{
${ }^{25}$ In theory, variable returns to scale - initially increasing, then decreasing - could also give rise to the coexistence of progressive and regressive transfers. One would see the regressive transfers at the low end of the wealth distribution, as poor herders seek to hand over their herd to the bigger herders, and the progressive at the upper tail as the wealthy herders reduce their herds through transfers to smaller neighbors. We know of no empirical evidence to support the variable returns hypothesis in this setting, however, and each of the several animal scientists we asked discounted this explanation as highly unlikely. Among other reasons, there would exist serious agency problems (the transferee could sell or slaughter the extra animals and simply claim they were eaten by wildlife predators), as similarly reflected in the lack of any significant hiring of herders (unlike in West Africa).
} 
thereby potentially creating or aggravating the resource appropriation externality and creating conflict risk. The same argument works in the opposite direction, causing $\beta_{k i}=\beta_{k j}=0$.

So let us now summarize by considering the feasible options in strategy space in turn. The top row of Figure 3 presents the cases where $m^{k}=0$, in which case no strategic complementarity exists, so $\beta_{i j}=0$. Since there is no prospect of security externalities, the only manipulative transfers that could exist in equilibrium would be regressive transfers meant to relieve the resource appropriation externality. These will necessarily only be offered if $j$ 's gift induces $i$ to migrate while $j$ remains at the base camp $\left(m^{i}=1, m^{j}=0\right)$. In this setting, transfers represent a Coasian mechanism to resolve the resource appropriation externality. Such regressive transfers could, in theory, occur regardless of whether $k$ migrates to the satellite area. However, because $L^{* i}{ }_{\mid m k=1} \geq L^{* i}{ }_{\mid m k=0}$ following Proposition $4, \beta_{j i}{ }^{\min }{ }_{\mid m k=1} \geq \beta_{j i}{ }^{\min }{ }_{\mid m k=0}$. In words, the transfer necessary to induce $i$ to vacate the base area is necessarily larger when $i$ expects to then face $k$ in a contested satellite area. This necessarily implies that regressive transfers to a pastoralist who then has to fight for his grazing land are both less likely and, when they occur, larger than regressive transfers to those who do not ultimately have to fight. ${ }^{26}$

The possibility for limited progressive manipulative transfers arises when $L^{i} \geq L^{* i}{ }_{\mid m k=1}$ and $L^{k} \geq L^{* k}{ }_{\mid m i=1}$, so that there is known positive probability of ethnic violence in the contested or open access grazing areas. Under those conditions, strategic transfers within a social group may be mutually advantageous to $i$ and $j$. Progressive interhousehold transfers intended by $\mathrm{i}$ to induce $\mathrm{j}$ to migrate and fight alongside him necessarily occur only if all parties ultimately move to the satellite area, fostering ethnic conflict over scarce resources $\left(m^{i}=m^{j}=m^{k}=1\right)$, as shown in Figure 3.

Figure 4 depicts the relevant $\beta_{i j}{ }^{m i n}$ and $\beta_{i j}{ }^{m a x}$ curves for a given set of parameters $\left\{L^{i}, L^{j}, L^{k}\right.$, $\left.r f_{a}, f_{a}, \theta, \tau\right\}$. The shaded area reflects the set of feasible progressive transfer in equilibrium, which

\footnotetext{
${ }^{26}$ For the sake of completeness, we note that when $L^{i}<L^{* i}$, so that $m^{i}=0$, it follows that $m^{k}=0$ if $L^{k}<L^{* k} \mid m^{i}=$ $m^{j}=0$ and $m^{k}=1$ if $L^{k} \geq L^{* k} \mid m^{i}=m^{j}=0$. In words, herder $k$ moves if he has a large enough herd size and there is no strategic interdependence. Similarly, if $L^{k}<L_{\mid m i=1}^{* k}$, then $m^{k}=0$ regardless of whether $L^{j} \geq L^{* j}$.
} 
depends on how $i$ and $j$ interact. For ease of exposition, we hereafter assume $i$ chooses $\beta_{i j}$ unilaterally, subject to satisfying j's incentive compatibility constraint to migrate, implying that $\beta_{i j}=\beta_{i j}{ }^{m i n} .{ }^{27}$ As defined earlier, $\beta_{i j}{ }^{\text {min }}$ is a linear, decreasing function of $L^{j}$ with unit slope in absolute value that is positive only below $L^{* j}{ }^{28}$ The willingness-to-transfer function, $\beta_{i j}{ }^{\max }$, can never be positive below $L^{*_{i}}$, and is concave in $L^{i}$ thereafter, increasing so long as the marginal change in the appropriation externality is dominated by the marginal change in the security externality, thus increasing expected per animal productivity for $i$ :

(18) $\frac{\partial \eta_{s}}{\partial L^{j}}\left(1-m^{k} \Phi\left(\frac{L^{i}}{L^{i}+L^{j}}\right)\right)+\frac{\partial \Phi}{\partial L^{j}}\left(1-\eta_{s}\right)<0$

The result is that not only are transfers limited to within the social group, but the fact that $\beta_{i j}{ }^{\max }$ is decreasing in $\mathrm{L}^{\mathrm{i}}$ beyond some threshold point and that $\beta_{i j}{ }^{m i n}$ is decreasing in $L^{j}$ limits the wealth space within which progressive interhousehold transfers will occur as well. The poorest pastoralists (e.g., those in the neighborhood of $L^{j}=0$ in Figure 4) will receive no wealth transfers and the biggest herders will make no transfers. This is a limited rational egalitarianism in which distributionally progressive transfers flow from an "upper middle class" to a "lower middle class" as a result of agents' identity-dependent strategic interdependence. This model thus yields empirically testable hypotheses that contrast with both the insurance model prediction, where net transfers covary positively with asset shocks but are unrelated to wealth, and with the prediction of the canonical altruism model, where net transfers are monotonically increasing in wealth. We leave for future work empirical investigation to try to identify what proportion of observed transfers is best explained by each model.

The set $\left[\beta_{i j}{ }^{m i n}, \beta_{i j}{ }^{m a x}\right]$ may be empty. Figure 5 depicts how a decrease in $L_{s}{ }^{\max }$, the satellite area carrying capacity, might extinguish transfers in equilibrium. ${ }^{29}$ Because more rival animals

\footnotetext{
${ }^{27}$ Given a finite set of fellow community members, however, $j$ may enjoy some bargaining power and be able to extract a greater transfer, although never beyond the $\beta_{i j}{ }^{m a x}$ individual rationality constraint imposed by $i$ 's choice problem. We leave this bargaining game refinement to future work.

${ }^{28}$ Recall from section 3 that the exogenous factors, including the ex ante herd distribution, determine $L^{* j}$ by establishing the differential range productivity, fixed and variable movement costs, and the range appropriation and physical security externality values. So $\beta_{i j}{ }^{m i n}$ changes with those parameters too.

${ }^{29} \mathrm{We}$ assume that the decrease in carrying capacity is not sufficient to induce $k$ not to migrate.
} 
occupy the rangeland, $L^{*_{i}}$ and $L^{*_{j}}$ both increase, per proposition 3 , and the resource appropriation externality effect becomes more pronounced, diminishing the prospective benefits to $i$ of a migration by $j$. Relative to the base case depicted in Figure 4, this increases $\beta_{i j}{ }^{\text {min }}$ and decreases $\beta_{i j}{ }^{\max }$ for any $\left\{\mathrm{L}^{\mathrm{i}}, \mathrm{L}^{\mathrm{j}}\right\}$, potentially extinguishing herder $i$ 's incentive to manipulate $j$ 's migration choice through a stock transfer.

A situation where no equilibrium transfers occur is more likely to arise as the exogenous risk of raiding parameter increases, the carrying capacity at the satellite area decreases (leaving no scope for cases where the induced positive security externality surpasses the negative competition externality), the base-satellite productivity differences are low and the level of food transfers is high. Such parameter value shifts reflect the stylized changes over the past generation in conditions on the east African rangelands described in section 2 and may help explain the apparent reduction in interhousehold transfers observed among pastoralists there.

\section{Conclusions}

The model developed in this paper effectively reconciles ethnographers' observations a generation or more ago of significant livestock transfers between pastoralists, with contemporary econometric evidence that interhousehold transfers are exceedingly small in volume, offer meager insurance against asset loss, and commonly flow from poorer to richer households rather than vice versa. Based on a model that integrates interhousehold transfer behavior with individuals' interdependent migration decisions, we establish an alternative underlying source of the decline in scope, size and frequency of interhousehold transfers among pastoralists. Our model exposes how exogenous changes (in carrying capacity, violence, food aid, etc.) have played a critical role in sharply reducing interhousehold wealth transfers among pastoralists. This hypothesis is the only one we can find that is consistent with the mass of ethnographic, range science and economic evidence on which we draw. Unfortunately, it is not itself directly testable with 
available data. Nor would we expect new data to shed much light on this phenomenon since we are trying to explain an important phenomenon that has largely vanished, it seems. The theoretical model nonetheless provides an alternative, integrated understanding of pastoralists' migration and interhousehold transfer behavior with significant policy implications.

A fundamental implication of our model is that the apparent decline in interhousehold transfers need not reflect declining solidarity or morality within pastoral communities. The intraethnic group transfers long observed in these settings can be explained satisfactorily as the rational calculus of pastoralists willing, de facto, to pay their friends and neighbors to do battle with them or to vacate a shared space that is otherwise overcrowded. The fact that such voluntary exchanges take place less frequently today than previously can then be understood as a natural consequence of changing environmental conditions rather than as a sign of cultural decline.

The implication, of course, is that policy and project interventions can further change the biophysical and socioeconomic environment in which pastoralists make migration and transfer choices, perhaps encouraging a renaissance in progressive interhousehold transfers or maybe (unintentionally) further discouraging such acts. Our model suggests that the provision of townspecific public services - modeled here as police protection and food aid distribution - induces a natural decline in private giving. While welfare may be increased due to the provision of public services and external transfers and the displacement effect need not be one for one, the incentives to undertake manipulative transfers decline. These incentives could be reversed through other public investments not yet taken. In particular, interventions to reduce inter-group violence e.g., through serious conflict resolution intermediation efforts or the geographic expansion of police protection - and to maintain or increase rangeland carrying capacity through improved water and range management can stimulate pastoralist mobility, which remains the key to welfare and wealth accumulation among these peoples, and thereby encourage anew progressive interhousehold transfers. 
Figure 1: Productivity and Income at Different Sites

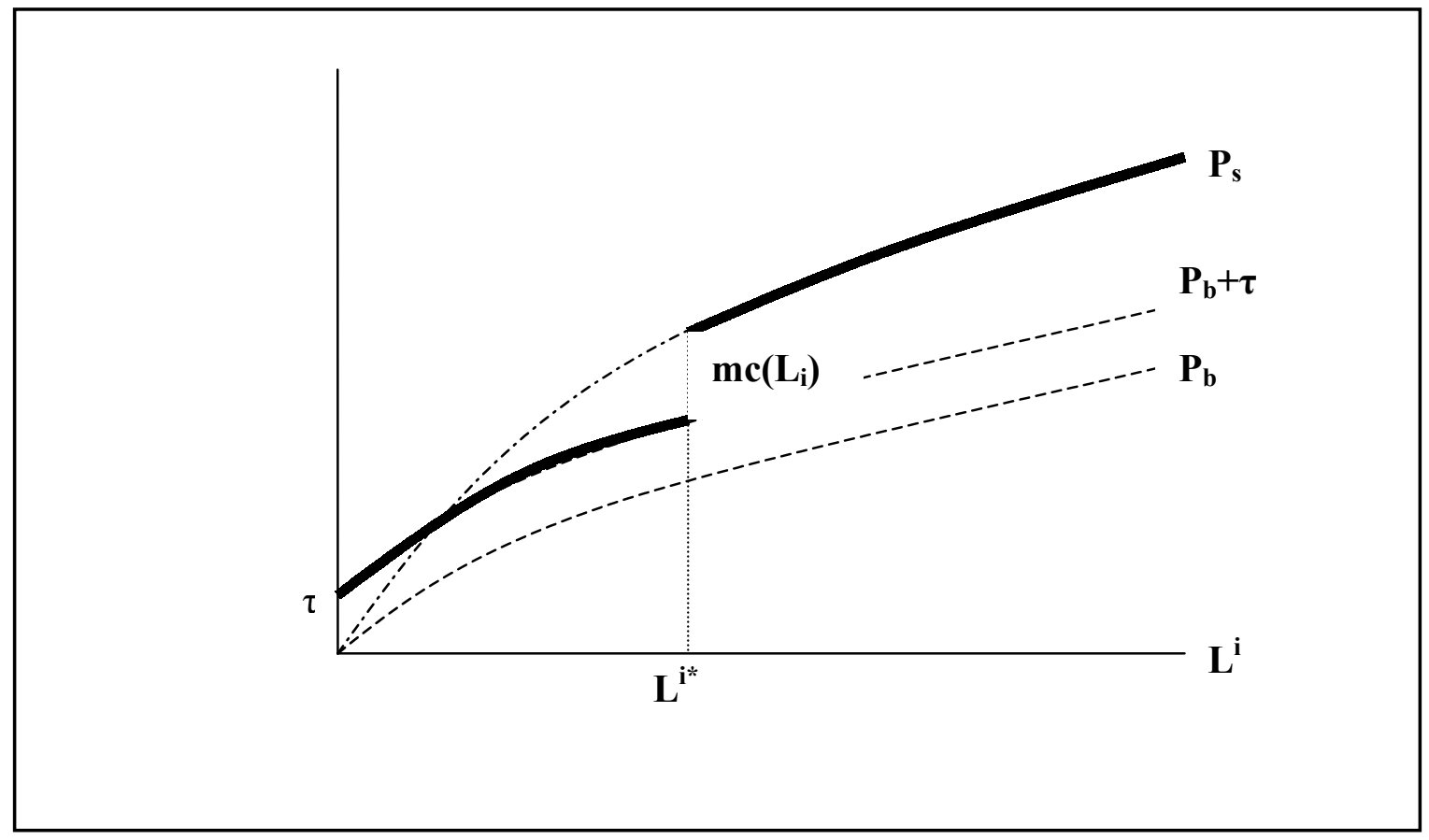

Figure 2: Piecewise Concave, Globally Convex Expected Income

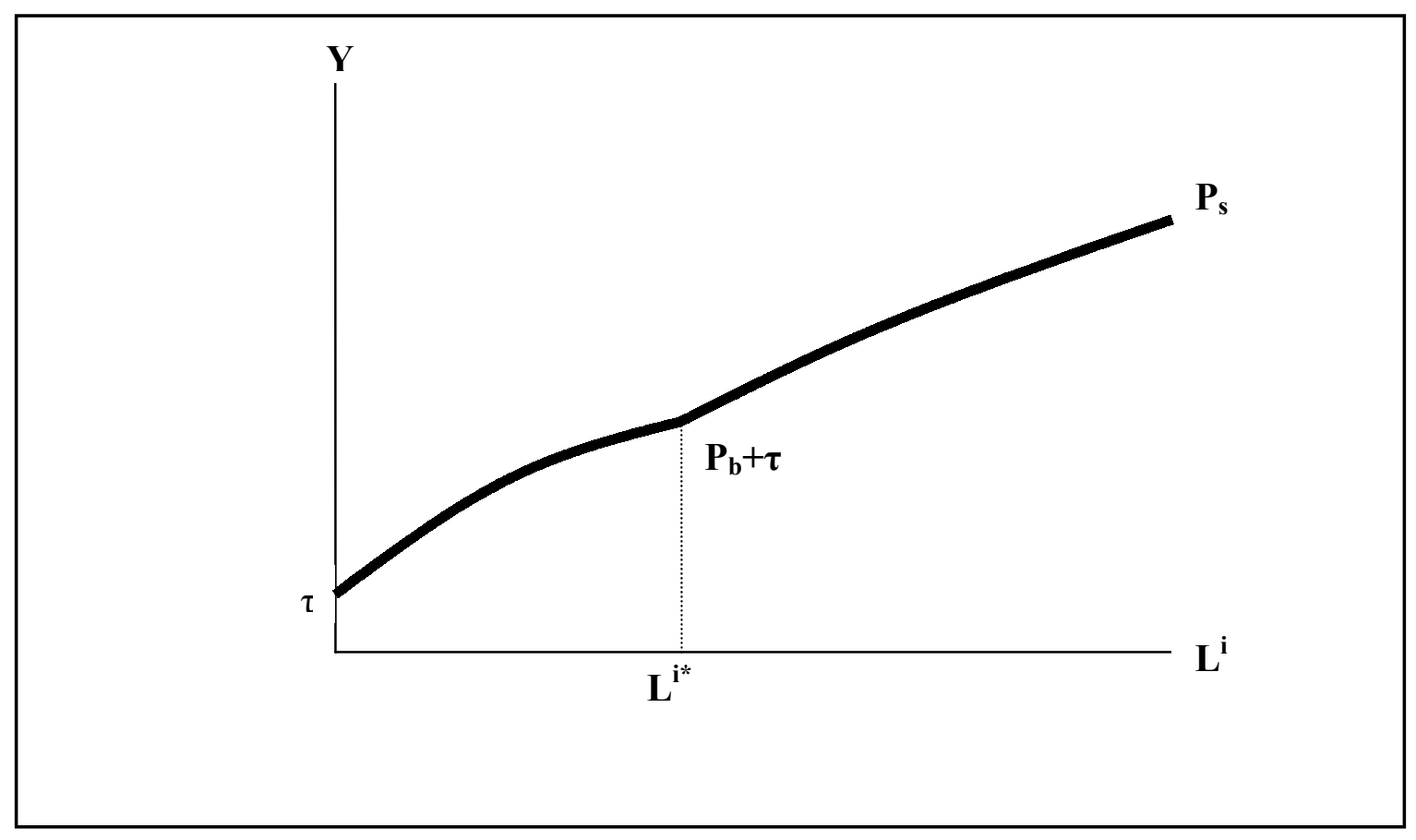


Figure 3: Equilibrium Transfers Conditional on Optimal Ex Post Migration Choices (cell entries are the value of the transfer)

\begin{tabular}{|c|c|c|c|}
\hline & & \multicolumn{2}{|c|}{$M^{i}=1$} \\
\hline & $M^{j}=0$ & $M^{j}=0$ & $M^{j}=1$ \\
\hline$M^{k}=0$ & 0 & $\begin{array}{c}\text { Regressive transfers } \\
0 \text { if } \beta_{j i}{ }^{{ }^{i n}}=0 \text { or if } \\
{\left[\beta_{j i}{ }^{m i n}>0, \beta_{j i}{ }^{m a x}\right]=\varnothing} \\
{\left[\beta_{j i}{ }^{m i n}, \beta_{j i}{ }^{m a x}\right] \text { otherwise }}\end{array}$ & 0 \\
\hline$M^{k}=1$ & 0 & $\begin{array}{c}\text { Regressive transfers } \\
0 \text { if } \beta_{j i}{ }^{m i n}=0 \text { or if } \\
{\left[\beta_{j i}{ }^{m i n}>0, \beta_{j i}{ }^{m a x}\right]=\varnothing} \\
{\left[\beta_{j i}{ }^{m i n}, \beta_{j i}{ }^{m a x}\right] \text { otherwise }} \\
\underline{\text { No Progressive Transfers }} \\
0 \text { if }\left[\beta_{i j}{ }^{{ }^{i n}}>0, \beta_{i j}{ }^{\max }\right]=\varnothing\end{array}$ & $\begin{array}{c}\text { Progressive transfers } \\
0 \text { if } \beta_{i j}{ }^{\min }=0 \\
{\left[\beta_{i j}{ }^{m i n}, \beta_{i j}{ }^{\text {max }}\right] \text { otherwise }}\end{array}$ \\
\hline
\end{tabular}


Figure 4: Limited Progressive Transfers in Equilibrium (conditional on $\mathrm{m}^{\mathrm{i}}=\mathrm{m}^{\mathrm{k}}=1$ )

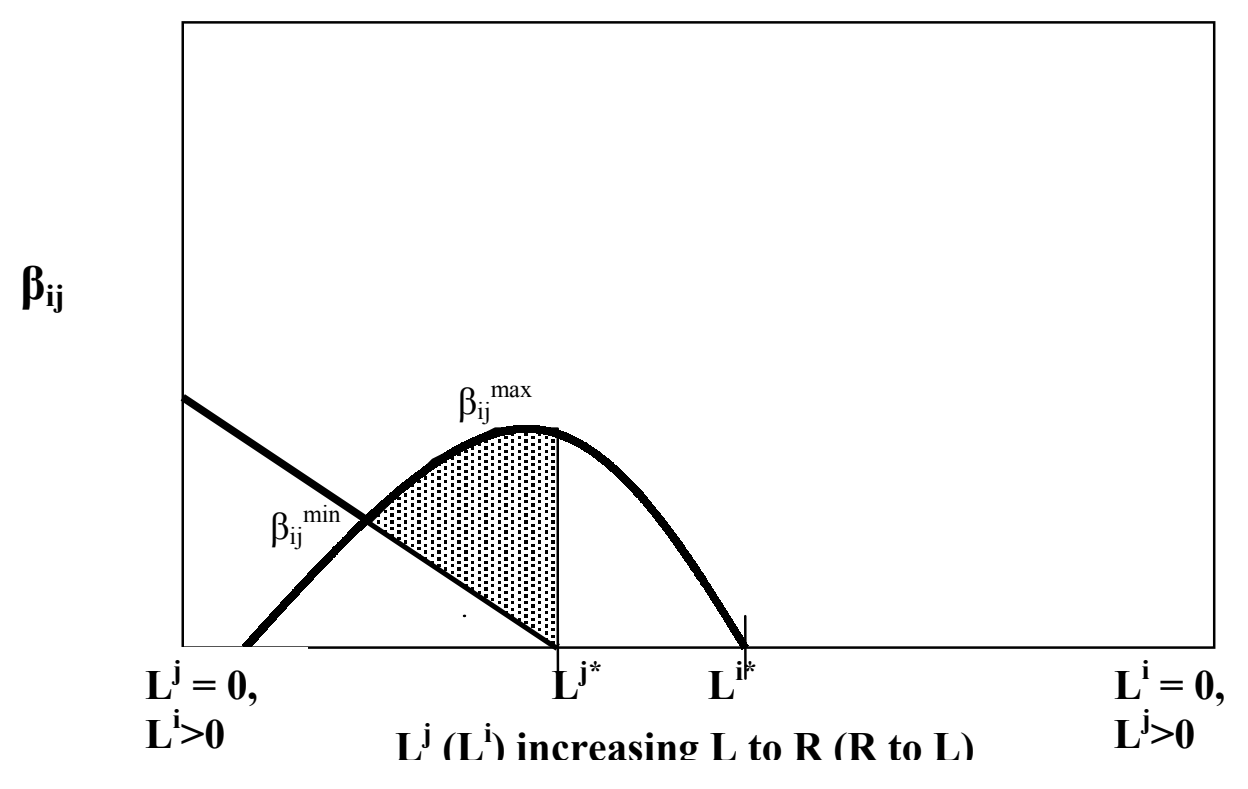

Figure 5: No Equilibrium Transfers (conditional on $\mathrm{m}^{\mathrm{i}}=\mathrm{m}^{\mathrm{k}}=1$ )

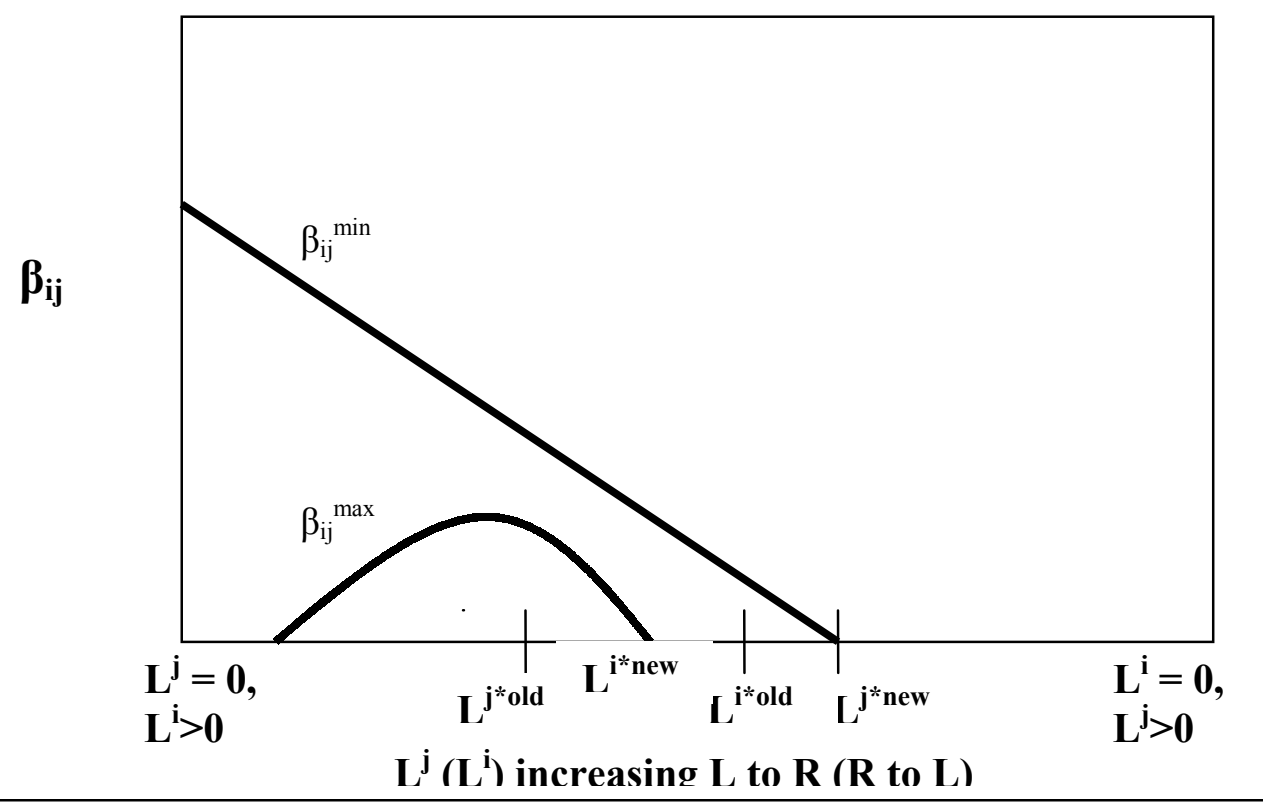




\section{References}

Akerlof, George (1982), "Labor Contracts as Partial Gift Exchange," Quarterly Journal of Economics 87: 543-569.

Andreoni, James (1989), “Giving With Impure Altruism: Applications To Charity and Ricardian Equivalence," Journal of Political Economy 97 (5): 1447-1458.

Banerjee, Abhijit V. and Andrew F. Newman (1993), “Occupational Choice and the Process of Development," Journal of Political Economy 101 (2): 274-298.

Behnke, Roy, Ian Scoones and Carol Kerven, eds.(1993), Range Ecology at Disequilibrium: new models of natural variability and pastoral adaptation in African Savannas. London: Overseas Development Institute.

Bernheim, Douglas B., Andrei Shleifer and Lawrence Summers (1985), "The Strategic Bequest Motive," Journal of Political Economy 93 (6): 1045-1076.

Bollig, M. (1992), "Ethnic Conflict in North-West Kenya: Pokot-Turkana Raiding 1969-1984," Zeitschrift fur Ethnologie 115.

Butler, Joseph (1726), Fifteen Sermons Preached at the Rolls Chapel. London: W. Botham.

Caputo, John D. and Michael J. Scanlon (1999), God, the gift, and postmodernism. Bloomington: Indiana University Press.

Coate, Stephen (1995), “Altruism, the Samaritan's Dilemma and Government Transfer Policy," American Economic Review 85 (1): 46-57.

Coate, Stephen and Martin Ravallion (1993), "Reciprocity Without Commitment," Journal of Development Economics 40 (1): 1-24.

Coppock, D. Layne, ed. (1994), The Borana Plateau of Southern Ethiopia: Synthesis of Pastoral Research, Development and Change, 1980-91. International Livestock Centre for Africa Systems Study 5.

Cox, D. (1987), “Motives for Private Income Transfers," Journal of Political Economy 95 (31): $508-546$. 
Deaton, Angus (1997), The Analysis of Household Surveys: A Microeconometric Approach to Development Policy. Baltimore: John Hopkins University Press.

Desta, Solomon (1999), Diversification of Livestock Assets for Risk Management in the Borana Pastoral System of Southern Ethiopia. PhD dissertation, Utah State University.

Ellis, James E., and David M. Swift (1988), "Stability of African Pastoral Ecosystems: Alternate paradigms and implications for development," Journal of Range Management, 41(6): $450-459$.

Ensminger, Jean (1992), Making a market: The institutional transformation of an African society. Cambridge: Cambridge University Press.

Fafchamps, Marcel (1992), "Solidarity Networks in Preindustrial Societies: Rational Peasants with a Moral Economy," Economic Development and Cultural Change 41 (1): 147-174.

Fehr, Ernst et al. (1997), "Reciprocity as a contract enforcement device: experimental evidence," Econometrica 65(July): 833-860.

Fleisher, Michael L. (1999), "Cattle raiding and household demography among the Kuria of Tanzania," Africa 69 (2): 238-255.

Fleisher, Michael L. (2000), Kuria cattle raiders: violence and vigilantism on the Tanzania/Kenya frontier. Ann Arbor: University of Michigan Press.

Foster, Andrew and Mark Rosenzweig (2001), "Imperfect Commitment, Altruism and the Family: Evidence from Transfer Behavior in Low-Income Rural Areas," Review of Economics and Statistics 83 (3): 389-407.

Goodhue, R.E., and N. McCarthy (1999), "Fuzzy Access: Modeling Grazing Rights in SubSaharan Africa" in B.Swallow, P. Hazell and N. McCarthy, eds., Property Rights, Risk, \& Livestock Development in Africa, Washington: International Food Policy Research Institute. 
Heald, Suzette (1999), “Agricultural intensification and the decline of pastoralism: A case study from Kenya," Africa 69 (2): 213-237.

Hendrickson, Dylan, Robin Mearns and Jeremy Armon (1996), "Livestock Raiding Among the Pastoral Turkana of Kenya," IDS Bulletin 27 (3): 17-30.

Hobbes, Thomas (1650), Humane nature London : John Holden.

Hobbes, Thomas (1651), Leviathan. London: Andrew Crooke.

Hussein, Karim, James Sumberg and David Seedon (1999), "Increasing Violent Conflict between Herders and Farmers in Africa: Claims and Evidence," Development Policy Review 17, 4: $397-418$.

Kimball, Miles S. (1988), "Farmers' Cooperatives as Behavior toward Risk," American Economic Review 78 (1): 224-32.

Kirchler, Erich, Fehr Ernst and Robert Evans (1996), "Social exchange in the labor market: Reciprocity and trust versus egoistic money maximization," Journal of Economic Psychology 17 (3): 313-41.

Legesse, Asmarom (1989) "Adaptation, Drought and Development: Boran and Gabra Pastoralists of Northern Kenya" in African Food Systems in Crisis. Volume 1: Microperspectives. Gordon and Breach, NY .

Little, Peter D. (1992) The elusive granary: herder, farmer, and state in northern Kenya. Cambridge: Cambridge University Press.

Little, Peter D., Kevin Smith, Barbara A. Cellarius, D. Layne Coppock and Christopher B. Barrett (2001), “Avoiding Disaster: Diversification and Risk Management Among East African Herders," Development and Change, 32, 3: 401-433.

Lundborg, Per (1998) "Foreign Aid and International Support as a Gift Exchange," Economics and Politics, 10(2): 127-141. 
Lybbert, Travis J., Christopher B. Barrett, Solomon Desta, and D. Layne Coppock, (2001) "Pastoral Risk and Wealth-Differentiated Herd Accumulation Patterns in Southern Ethiopia," unpublished Cornell University manuscript.

Markakis, J, ed. (1993) Conflict and the Decline in Pastoralism in the Horn of Africa. London: Macmillan.

Mauss, Marcel (1966), The gift; forms and functions of exchange in archaic societies. London: Cohen \& West.

McCabe, J. Terrence (1987) Drought and Recovery: Livestock dynamics among the Ngisonyoka Turkana of Kenya. Human Ecology. 15:317-329.

McPeak, John G. (2001a), “Confronting the Risk of Asset Loss: livestock transfers in northern Kenya." Cornell University unpublished manuscript.

McPeak, John G. (2001b), “Analyzing and Addressing Localized Degradation in the Commons" Cornell University unpublished manuscript.

McPeak, John G. and Christopher B. Barrett (2001), "Differential Risk Exposure and Stochastic Poverty Traps Among East African Pastoralists," American Journal of Agricultural Economics, 83 (3): 674-679.

Milbank, John (1997), The word made strange : theology, language, and culture. Cambridge, MA: Blackwell Publishers.

Muiruri, Stephen (2001), 'Thirty killed in raid," [Nairobi] Daily Nation, February 9 edition, online at http://www.nationaudio.com/News/DailyNation/Today/News/News89.html.

Nathan, M.A., E.M. Fratkin, and E.A. Roth (1996), 'Sedentism and Child Health among Rendille Pastoralists of Northern Kenya,' Social Science and Medicine, 43, 4: 503-515.

Oba, Gufu (1992), Ecological factors in Land Use Conflicts, Land Administration and Food Insecurity in Turkana, Kenya. Pastoral Development Network Paper number 33a. London: Overseas Development Institute. 
Offer, Avner (1997), "Between the gift and the market: the economy of regard," Economic History Review 3 (1997): 450-476.

O’Leary, M.F. (1987), “Responses to Drought in Northern Kenya: the Rendille and Gabra livestock producers," in P.W. Baxter, ed., Property, Poverty and People: changing rights in property and problems of pastoral development, Manchester: Department of Social Anthropology and International Development Center, University of Manchester.

Osamba, Joshia O. (2000) “The Sociology of Insecurity: Cattle Rustling and Banditry in NorthWestern Kenya," African Journal on Conflict Resolution 1, 2 (online at http://www.accord.org.za/publications/j2/kenya.htm).

Phelps, Edmund S. ed. (1975), Altruism, Morality and Economic Theory (New York: Russell Sage Foundation).

Platteau, Jean-Philippe (1995), "Framework for the Analysis of Evolving Patron-Client Ties in Agrarian Economies," World Development 23 (5): 767-86.

Platteau, Jean-Philippe (2000), Institutions, Social Norms, and Economic Development. Amsterdam: Harwood Academic Publishers.

Ray, Debraj (1998), Development Economics. Princeton: Princeton University Press.

Robinson, P. (1984) Gabbra Nomadic Pastoralism in Nineteenth and Twentieth Century Northern Kenya: strategies for survival in a marginal environment, unpublished Ph.D dissertation, Northwestern University.

Samuelson, Paul A. (1993), “Altruism as a Problem Involving Group Versus Individual Selection in Economics and Biology," American Economic Review 83 (2): 143-148.

Schneider, Harold K. (1979), Livestock and equality in East Africa: the economic basis for social structure. Bloomington: Indiana University Press.

Schwartz, H.J., S. Shaabani, and D. Walther (1991), Range Management Handbook of Kenya Volume II-1, Marsabit District, Republic of Kenya, Nairobi: Ministry of Livestock Development. 
Smith, Kevin, Christopher B. Barrett, and Paul W. Box (2001), "Not Necessarily In The Same Boat: Heterogeneous Risk Assessment Among East African Pastoralists," Journal of Development Studies, 37 (5): 1-30.

Smith, Vincent H. Michael R. Kehoe and Mary E. Cremer (1995), “The Private Provision of Public Goods: Altruism and Voluntary Giving," Journal of Public Economics 58 (1): 107-126.

Sobania, N.W. (1979) Background History of the Mt. Kulal Region of Kenya. Nairobi. UNESCO. IPAL report A-3.

Spear, T. and R. Waller, eds., (1993) Being Maasai. London: James Currey.

Sperling, Louise. PhD thesis from UCLA

Tablino, P. (1999) The Gabra: Camel Nomads of Northern Kenya, Limuru, Kenya: Paulines Publications Africa.

Torry, W.I. (1973). Subsistence Ecology Among the Gabra: Nomads of the Kenya / Ethiopia frontier. Department of Anthropology. New York, Columbia University.

Townsend, Robert (1994), "Risk and insurance in village India," Econometrica 62 (3): 539-591. 